\title{
Gross Pathologic Examination
}

National Cancer Institute

\section{Source}

National Cancer Institute. Gross Pathologic Examination. NCI Thesaurus. Code C90390.

An assessment of macroscopic pathological findings that are caused by disease. 